\title{
EDUCAÇÃO SUPERIOR ENTRE FORMAÇÃO E PERFORMANCE
}

\author{
Pedro Goergen*
}

\begin{abstract}
*Professor titular da Universidade de Sorocaba e Professor titular da Universidade Estadual de Campinas é autor de vários livros, capítulos de livro e artigos em revistas especializadas sobre ética, formação de professores e educação superior. E-mail: pedro.goergen@prof.uniso.br

Resumo: Neste texto, são apresentadas algumas questões de natureza filosófica sobre os pressupostos da avaliação de instituições de educação superior. $\mathrm{O}$ autor critica os processos avaliativos que se fundamentam num conceito de qualidade referenciado à eficiência ajustada ao sistema e defende a necessidade de uma reflexão mais aprofundada sobre o ideal de ser humano e de sociedade enquanto paradigmas de qualidade e de pertinência social.
\end{abstract}

Palavras-chave: Educação superior. Avaliação. Qualidade. Responsabilidade social.

HIGHER EDUCATION - BETWEEN PERSONAL DEVELOPMENT AND PERFORMANCE

\begin{abstract}
This paper presents few phylosophical questions about the pressupposition evaluation in the higher education. The author criticizes the evaluative processes that is founded in the concept of quality with reference to efficiency adjusted to the system, and defends the necessity of a deeper reflection about the ideal about the human being and the society as long as paradigms of quality and social pertinence.
\end{abstract}

Key words: Higher education. Evaluation. Quality. Social responsability.

Já nos anos sessenta do século passado, os estudantes, inspirados no pensamento crítico e engajado de Adorno, Horkheimer e Marcuse, sinalizaram que havia chegado a hora de rever as posturas autoritárias e distanciadas da realidade de algumas instituições sociais, entre elas a universidade. Surgia naquele momento um novo modelo de relacionamento entre a universidade e a sociedade que seria desenvolvido nas décadas seguintes. Com isso, alteravamse, também, os critérios de avaliação das instituições de ensino superior cujas atividades, de ora em diante, teriam que se mostrar profícuas para a solução das carências e expectativas sociais. Era o prenúncio de um amplo processo de reformas, balizado pelos novos rumos da sociedade globalizada e pela crescente percepção dos limites do modelo de desenvolvimento iluminista, há tempos assumido pela universidade.

Globalização, desigualdade social, desenvolvimento sustentado, riscos ambientais, bem como os rumos da ciência $\&$ tecnologia com seus reflexos 
sobre a vida individual, coletiva e planetária compõem um cenário que exige uma profunda reforma do pensamento e do comportamento da sociedade. Aos poucos se delineia no horizonte a questão central do nosso tempo: como alcançar um modelo de desenvolvimento que inclua a todos, que desenvolva o homem em sua integralidade e que seja sustentável. Esse enorme desafio impõe-se também às instituições de educação superior, agora chamadas a contribuir mais diretamente para o desenvolvimento social no campo da ciência e tecnologia, da formação dos futuros cidadãos e da construção de uma nova cultura.

Se é certo que os temas da globalização, do desenvolvimento sustentável e da degradação do meio ambiente ganharam grande visibilidade discursiva, é também verdade que a educação superior, no que tange às suas práticas de ensino e pesquisa, continuava basicamente a mesma. O mandado de pertinência social era atendido por projetos pontuais de extensão que mais simulavam do que efetivavam uma instituição socialmente pertinente. Os impulsos de transformação estrutural das instituições de educação tiveram que ser, de certo modo, impostos de fora pela opinião pública e pelos gestores das políticas oficiais. Esta pressão externa e a crescente consciência interna firmaram o mandado da responsabilidade social, colocando a educação superior diante do desafio de refletir criticamente, à luz desse novo cenário, sobre suas atividades de ensino e de pesquisa, bem como sobre suas práticas culturais.

Lentamente foi ficando claro para todos que as instituições de educação superior não poderiam seguir alheias aos temas e preocupações de grande urgência para a sociedade em geral e para cada indivíduo em particular como a paz, o meio ambiente, a interculturalidade, a transdisciplinaridade, o desenvolvimento sustentável. Com base em novos procedimentos pertinentes à ordem das disciplinas e suas estruturas internas, à relação entre ciência e tecnologia e à formação profissional num contexto cultural profundamente transformado, é preciso projetar uma nova imagem das instituições da educação superior, de suas práticas de investigação e de ensino, plenamente conscientes de sua responsabilidade social.

Hoje já dispomos de um repertório bastante amplo de conceitos que buscam captar esse novo desafio da pesquisa, do ensino e da cultura. Fala-se em inserção, pertinência, compromisso, responsabilidade e sentido sociais. Para além das diferenças, todos esses termos sinalizam claramente um novo modelo institucional comprometido com o meio no qual está inserido. Inicialmente, esse novo mandado foi interpretado como a necessidade de adaptação institucional aos paradigmas políticos, econômicos e científico-tecnológicos ou mesmo hegemônicos. Essa falácia da adaptação ao real, do colocar-se a serviço do 
modelo político-econômico vigente foi sendo, aos poucos, revista à luz das críticas que, de todos os lados, se impunham ao modelo sócio-econômico cujos resultados se revelam cada vez mais insustentáveis.

Noutras palavras, responsabilidade ou pertinência social implicam sempre um posicionamento crítico com relação à realidade na perspectiva dos ideais humanitários de justiça social, liberdade, paz e desenvolvimento sustentado com tudo o que isso representa em termos de organização social, de desenvolvimento científico-tecnológico, de acesso aos bens culturais e materiais, de respeito e desenvolvimento cultural para todos os cidadãos.

Outra conseqüência da interpretação pragmática da inserção social das instituições de educação superior foi o paroquialismo, ou seja, seu foco exagerado nos problemas de seu entorno imediato. Esquecia-se, com isso, que na sociedade contemporânea já não existem temas nem problemas que não tenham, sempre, também imbricações e ressonâncias de mundo, de universalidade, de totalidade. Hoje, não há mais instituições de ensino superior que tenham vocação apenas regional ou local em sentido estrito. O universal e o local imbricam-se de tal modo que já não se pode falar de ciência local, nem ensino local, nem formação local. O local sempre deve preservar a perspectiva universal e o universal sustentar-se no local. A qualidade e a pertinência social do ensino procedem da interatuação entre critérios universais, lidos e interpretados à luz da inserção espácio-temporal da instituição, que, presumivelmente, será o âmbito de atuação dos futuros profissionais.

Outra falácia que é preciso evitar é a tendência de se responsabilizar esse ou aquele segmento social pelo atraso e/ou desenvolvimento humano. Nenhum segmento pode ser responsabilizado sozinho pelas transformações. Esse foi o erro do pedagogismo que até hoje continua vivo entre nós. Também, não vão ser as instituições de educação superior universidade que hão de transformar o mundo. No entanto, essa difícil tarefa exige o empenho especial daquelas instâncias que desfrutam de condições privilegiadas de intervenção nos rumos da sociedade. Entre elas encontram-se as instituições de educação superior encarregadas de gerar e difundir os conhecimentos e formar profissionais-cidadãos capazes de liderar, nos campos de sua atuação, o processo de transformação social.

Para que isso venha a ocorrer, é necessário que elas se submetam a um amplo processo de auto-avaliação crítica, com o objetivo de discernir qual o papel que vêm exercendo e qual o papel que deveriam desempenhar na perspectiva de contribuir para a construção de uma sociedade mais digna, justa e humana. Em termos concretos, isso significa que as instituições de pesquisa e educação superior estão desafiadas a incluir nos seus processos de avaliação o critério 
de responsabilidade e pertinência social, ou seja, devem perguntar-se qual o sentido social de sua atuação nos campos da pesquisa, do ensino, da extensão e da cultura.

Com os desequilíbrios ambientais e as desigualdades sociais vêm à tona também a insuficiência e a incongruência dos paradigmas científicos tradicionais, com suas formas simplificadoras, disciplinárias e fragmentadas de conhecer. A ideologia do desenvolvimento, focada exclusivamente no econômico, ameaça provocar um colapso social e ecológico da civilização humana. Os sintomas de esgotamento de um estilo de desenvolvimento ecologicamente predador e socialmente injusto já são bastante conhecidos; importa agora descobrir, reconhecer e corrigir suas causas e isso representa uma alteração radical da visão de mundo, da relação do homem com a natureza e com a vida. Todos esses são temas de eminente relevância que apontam para muito além de uma leitura mecanicista e pragmática da pertinência social.

Diante dessa realidade, podemos recolocar a pergunta a respeito da responsabilidade ou pertinência social da atuação das nossas instituições de ensino superior. Trata-se de uma questão complexa cujas dificuldades vão muito além dos discursos altruístas e pragmaticamente afunilados, tão repetidos hoje. São graves as ambivalências que afetam a educação superior em geral e, em particular, a produção de ciência e tecnologia. É essa situação que nos permite insistir na tese de que as instituições de ensino superior necessitam, urgentemente, fazer uma auto-avaliação a respeito do sentido de sua atuação no campo da ciência e tecnologia para devolver ao humano sua centralidade, não permitindo que o conformismo científico elimine a consciência e a política.

Entenda-se política no sentido originário, referente à polis, ao lugar onde se vive, onde se cultiva as tradições, onde se coabita com os outros, onde se faz a própria história, se constrói a identidade. A ciência não pode tornar-se uma esfera autônoma que assume decisões sobre a vida e o destino do homem e do mundo à revelia de qualquer debate no âmbito da esfera política. Se for essa a opção, se não se respeitar o espaço humano de participação e decisão dos cidadãos cuja identidade e sentidos transcendem a lógica dos números, das equações, dos interesses econômicos, então as certezas científicas, a tecnicização e a instrumentalização da vida ameaçam de morte o indivíduo-cidadão.

Há conceitos matriciais da cultura contemporânea como 'progresso', 'ciência' e 'tecnologia' que assumiram traços profundamente ideológicos na medida em que se desviam dos reais interesses humanos. Isso precisa ser debatido publicamente quando se fala em ciência e tecnologia no contexto da educação superior. Seria falso pensar que essa incompatibilidade entre o 
epistêmico e o humano surge apenas no campo da aplicação prática da ciência e da tecnologia. Ao contrário, tais ambivalências se encontram na origem, ou seja, no modelo de racionalidade subjacente à ciência e tecnologia, cuja matriz lógico-matemática, técnica, instrumental e reducionista perpassa as práticas de pesquisa, de ensino e extensão das instituições de educação superior. E fomentam a paradigmática divisão das instituições de educação superior entre ciências exatas e humanas.

A educação superior, lugar por excelência do pensar, não pode jamais prender-se à lógica universalista da racionalidade cartesiana e nem identificar-se com o real quando, em seu nome, se ampliam e aceleram as injustiças. Entre as duas margens do universal e da pertinência, que balizam nosso conhecimento, abre-se o caminho para a responsabilidade social das instituições de ensino superior. Impõe-se, antes de tudo, fazer uma profunda reflexão crítica sobre o modelo epistêmico que rege o trabalho de investigação e pesquisa, procurando desvendar-lhe seus lados ocultos e ideológicos.

Com relação ao ensino é preciso objetivamente admitir que a educação superior tem como tarefa fazer a intermediação entre o indivíduo e a sociedade, preparando-o, em termos de conhecimentos, habilidades e capacidade de aprendizagem permanente, para atender às demandas do mercado de trabalho. Por mais justificadas que sejam as críticas com relação a essa incumbência, dificilmente as instituições de ensino superior poderão declinar dela. De outra parte, tal encargo não pode desconsiderar as dimensões ético-políticas do ser humano. Partindo do princípio de que a construção de uma sociedade mais justa e democrática depende de cidadãos não só profissionalmente competentes, mas também de cidadãos que tenham apurado sentido ético e responsabilidade social, a universidade deve formar sujeitos críticos, autônomos e socialmente responsáveis. O equilíbrio entre essas duas dimensões da formação - a competência técnica e a consciência ética - representa o critério definidor de um ensino socialmente relevante.

A comunidade acadêmica necessita conscientizar-se de que o paradigma do desenvolvimento mecânico e linear, voltado exclusivamente ao crescimento econômico, deve transitar para uma abordagem mais complexa, ética e trans-disciplinar que se preocupa com o ser humano. Nesse novo paradigma, o desafio será encontrar um equilíbrio entre o desenvolvimento econômico, social/humano e biofísico. O conceito de desenvolvimento sustentável criticamente revisado do ponto de vista ético-social, que resume numa só expressão todos esses aspectos, precisa tornar-se o centro regulador e aglutinador das atividades acadêmicas no âmbito da pesquisa, da docência, da prestação de 
serviços e mesmo das atividades culturais. Do ponto de vista da instituição de educação superior, a sustentabilidade deve orientar-se numa dupla dimensão de totalidade. Primeiro, a totalidade da própria universidade cujas atividades de investigação, docência, prestação de serviços e atividades culturais devem formar um conjunto orgânico e integrado e, segundo, a totalidade do desenvolvimento econômico, social, ético, ecológico e cultural.

A pergunta que se coloca é até que ponto os processos avaliativos captam estes aspectos centrais do ensino superior ou até que ponto eles apenas nos indicam em que medida as instituições estão adaptadas e instrumentalizadas para o sistema político-econômico vigente. Os processos avaliativos têm como pressuposto a pretensão de descobrir se uma instituição de educação superior é ou não de boa qualidade. Tal intenção supõe, evidentemente, um ideal do que seja uma boa instituição de educação superior. A dúvida que fica é se temos clareza a respeito do que designamos com o conceito de qualidade. Noutras palavras, temos clareza a respeito de qual ser humano queremos formar para qual modelo de sociedade?

Na medida em que a avaliação tem o papel de atuar construtivamente sobre a conformação e o desenvolvimento institucional, essa é uma pergunta fundamental. A sobrevalorização da numerologia, das estatísticas, do produtivismo quantitativo, da operacionalidade, da performatividade não estaria nos dando uma indicação do ideal de boa instituição que se encontra por detrás dos processos avaliativos? Em palavras mais diretas, o ideal de universidade que subjaz aos nossos processos avaliativos não é o de uma instituição eficiente na produção de conhecimentos e na formação de pessoas para o sistema, pouco importando a natureza dos conhecimentos, da formação e do sistema?

Parece não ser arriscado dizer que as nossas práticas avaliativas ainda carecem de uma reflexão mais aprofundada sobre os pressupostos ideológicos que se escondem por detrás dos números, das estatísticas e dos rankings. Não estaríamos carentes de uma reflexão filosófico-antropológica-política que nos pudesse dar algumas orientações a respeito do que estamos avaliando quando avaliamos e quais as implicações de nossa pratica avaliativa?

Se estivermos de acordo que as instituições de educação superior devem promover o desenvolvimento de um modelo de ciência e tecnologia condizente com os legítimos interesses humanos; se estivermos de acordo, também, que estas instituições devem formar cidadãos não só competentes, mas também eticamente responsáveis; se, enfim, estivermos de acordo que tais instituições, além da performatividade e da eficiência econômicas, devem promover o desenvolvimento humano e ambiental integral; então também devemos es- 
tar conscientes da necessidade de uma reforma de pensamento e de postura ante o conhecimento, seu manejo e aplicação; mais que isso, devemos estar conscientes, da necessidade de uma nova paidéia formativa que coloque em primeiro plano o sentido humano de ciência e tecnologia e os princípios de co-responsabilidade, solidariedade, justiça e eqüidade. A responsabilidade social da universidade não se restringe, portanto, à sua adaptação às demandas e urgências do mundo econômico como, por vezes, se supõe, mas implica em assumir a responsabilidade de repensar os sentidos de ciência e tecnologia e, portanto, os sentidos de investigação e da formação profissional. 